\title{
TRAJETÓRIAS E EXPERIÊNCIA DE ACESSO À PÓS-GRADUAÇÃO POR MEIO DE AÇÕES AFIRMATIVAS
}

\author{
Márcia Basília de Araújo \\ Instituto Federal de Minas Gerais (IFMG), Sabará, Minas Gerais, Brasil \\ SANTUZA AMORIM DA SILVA \\ Universidade do Estado de Minas Gerais (UEMG), Belo Horizonte, Minas Gerais, Brasil
}

\begin{abstract}
REsumo: Este artigo se debruça sobre o estudo de trajetórias de sujeitos negros e de meios populares que acessaram e concluíram Programas de Pós-Graduação Stricto Sensu (nível mestrado). Foram abordados sujeitos que tiveram o auxílio de um programa de ações afirmativas na pós-graduação, o Programa Internacional de Bolsas da Fundação Ford. Foram utilizados os recursos da pesquisa qualitativa, por meio da entrevista narrativa episódica e da construção de retratos sociológicos, aspecto que possibilitou conhecer e analisar as trajetórias escolares e de vida de cinco sujeitos(as). Para a construção de trajetórias tão longas quanto improváveis, os sujeitos investigados desenvolveram e reativaram suas disposições em vários espaços e momentos. Para tanto, contaram, além do próprio desejo, com a participação da escola, das famílias e dos movimentos sociais organizados, com destaque para o movimento negro.
\end{abstract}

Palavras-chave: Ações afirmativas. Pós-graduação. Trajetórias escolares. Movimentos sociais. Fundação Ford.

\section{INTRODUÇÃO}

Para compreendermos as questões das desigualdades existentes no Brasil, dentre outras possibilidades e indicadores sociais, é interessante nos voltarmos para o ensino superior brasileiro, visto que os cursos de graduação são celeiros da pósgraduação, de onde, obviamente, saem os alunos que farão cursos de pós-graduação. De acordo com dados do Instituto Brasileiro de Geografia e Estatística - IBGE (2018) existem diferenças significativas entre os estudantes que conseguem ingressar no ensino superior, tanto em relação à origem escolar quanto em relação à raça. Em 2017, do total de estudantes com ensino médio completo, $67,7 \%$ havia frequentado apenas a rede pública, $28,2 \%$ apenas a rede privada e $4,2 \%$ ambas as redes. Dentre aqueles que cursaram apenas a rede privada durante o ensino médio, $79,2 \%$ conseguiram acessar o ensino superior, enquanto a taxa de ingressantes egressos de escolas públicas foi de apenas $35,9 \%$. A taxa de ingresso no ensino superior de egressos de escolas privadas é mais que o dobro daquela obtida pelos egressos da rede pública.

Apesar das políticas de acesso e universalização do ensino superior adotadas nos últimos anos, o ingresso de estudantes pretos ou pardos ainda é bem menor do que 
o de estudantes brancos. É possível notar também que a desigualdade racial é mais acentuada entre aqueles que são oriundos do ensino médio público, pois a taxa de ingresso dos brancos foi de $42,7 \%$ enquanto a de pretos ou pardos não passou de $29,1 \%$. No entanto, analisando a taxa de ingresso dos estudantes da rede privada, notamos que as desigualdades ainda persistem se fizermos o recorte racial. Estudantes brancos oriundos da rede privada têm $81,9 \%$ de chances de ingressar no ensino superior, enquanto pretos e pardos provenientes da mesma rede de ensino têm $71,6 \%$.

Em relação à pós-graduação, de acordo com dados disponíveis no banco de dados online da CAPES (2018), no ano de 2014 o Brasil contava com 3748 programas de pós-graduação stricto sensu, aí contabilizados aqueles que ofertavam apenas o mestrado, mestrado e doutorado, apenas doutorado e somente mestrado profissional, sendo que a maior parte desses programas estava localizada nas regiões Sul e Sudeste (BRASIL, 2015). Em 2017, esse número subiu para 4296. De acordo com Silvério (2008, p. 215), além das disparidades regionais existe uma forte desigualdade social ao longo da existência da pós-graduação no Brasil pois

[...] esse sistema, no entanto, se consolidou sem atender as necessidades de desenvolvimento e crescimento de todas as regiões do país de forma igualitáia e, também, não conseguiu incorporar todos os segmentos da população brasileira, uma vez que houve tanto transferência indireta de renda, quanto reserva de mercado para os setores médios urbanos. Assim, ao invés de operar na diminuição das desigualdades, tanto regionais quanto étnicoraciais, ele as reproduzia e as intensificava.

Nesse contexto, o Programa Internacional de Bolsas, promovido no âmbito do setor não governamental, constituiu-se como um importante mecanismo de democratização desse espaço, pois possibilitou, ainda que de forma tímida, a inserção de homens e mulheres com potencial de liderança social na pós-graduação brasileira, trazendo para o debate questões capazes de suscitar novas discussões e tencionar esse meio.

Este artigo é resultado de uma dissertação de mestrado ${ }^{1}$ que buscou descrever e analisar trajetórias e experiências de sujeitos negros e de meios populares que realizaram cursos de mestrado, com o apoio do Programa Internacional de Bolsas da Fundação Ford (IFP). Para a realização da pesquisa, que deu origem ao texto, foram utilizados recursos da abordagem qualitativa, como a entrevista narrativa episódica (FLICK, 2002, 2009) e a construção de retratos sociológicos (LAHIRE, 2002, 2004).

A entrevista narrativa episódica, de acordo com Flick (2002, 2009), é indicada para pesquisas como a que realizamos porque possibilita que o entrevistado fale sobre si mesmo, com ênfase em questões e momentos específicos de sua trajetória ou experiência. O ponto de partida da entrevista episódica é a suposição de que o sujeito traz experiências sobre determinado domínio, fato ou momento, e pode, durante a entrevista, apresentar narrativas nas quais esse conhecimento apareça de forma mais organizada e próxima de experiências vividas. Diferente da entrevista narrativa, em que 
o entrevistado deverá falar livremente, na entrevista episódica o entrevistador deverá realizar intervenções que reforcem a ideia central e conduzam a narrativa até o final.

Os retratos sociológicos são construções que consideram que os indivíduos, embora devam ser compreendidos em suas singularidades, não podem ser considerados individualizados no sentido de estarem isolados das questões sociais que os constituem como sujeitos. Assim, o retrato possibilita a reconstituição de trajetórias individuais, buscando reencontrar os fios que ligaram (e ainda ligam) esses indivíduos aos quadros sociais nos quais se reconstituíram essas trajetórias (LAHIRE, 2004).

Para a análise das trajetórias buscou-se apoio nos conceitos de disposições (LAHIRE, 2002, 2004, 2005) e suportes (MARTUCCELLI, 2012). Disposições podem ser compreendidas como persistentes maneiras de ser, ou seja, são produtos de práticas socializadoras incorporadas e possuem um caráter de recorrência. Não se pode considerar um episódio isolado da vida de um sujeito como uma disposição, mas podese afirmar que as disposições se constitutem a partir de experiências relativamente semelhantes que se repetem. Já o conceito de suporte, também utilizado para compreender o percurso escolar longevo e exitoso dos sujeitos da pesquisa, indica a rede de apoio e proteção que os sujeitos mobilizam ao longo de suas trajetórias.

Além desta introdução, mais três partes compõem o texto. A primeira apresenta o Programa Internacional de Bolsas da Fundação Ford e sua importância como experiência bem sucedida de ação afirmativa, fora do âmbito do poder público, na pósgraduação brasileira; em seguida estão as trajetórias dos bolsistas, as disposições construídas e os suportes encontrados para o alcance da longevidade escolar. E, por fim, nas considerações finais, são apresentados os principais achados da pesquisa.

O PROGRAMA INTERNACIONAL DE BOLSAS DA FUNDAÇÃO FORD: UMA EXPERIÊNCIA BEM SUCEDIDA

Em cada país onde o Programa Internacional de Bolsas foi implementado, buscou-se consultores para colaborar com o desenvolvimento de uma proposta que contribuísse para o desenvolvimento da educação e de pesquisas, voltados para temas relacionados aos eixos temáticos da Fundação. Outra grande preocupação dos consultores era que esse programa pudesse contribuir para a inserção de grupos pouco representados nos programas de pós-graduação. Assim, no México e no Chile o Programa procurou privilegiar as populações indígenas. No Brasil, onde a Fundação já mantinha um bom relacionamento com os movimentos sociais e, sobretudo, com o movimento negro ${ }^{2}$, não foi difícil a aproximação com grupos que pudessem contribuir com a elaboração de um projeto de educação sólido, comprometido com a justiça e a transformação da realidade social.

A autora Araújo (2015), em consonância com Rosemberg e Andrade (2008), afirma que o Programa Internacional de Bolsas da Fundação Ford - International Fellowships Programa (Programa IFP) teve, desde o seu lançamento, grande relevância para a democratização do acesso e permanência na pós-graduação brasileira, pois até o ano de 2013 esse programa ainda era uma das poucas experiências de ação afirmativa nesse segmento da educação no Brasil. É importante ressaltar que em 2013 foi criado o Programa "Abdias Nascimento", cujo objetivo foi promover o desenvolvimento acadêmico de grupos específicos, como os autodeclarados pretos, pardos, indígenas, 
estudantes com deficiência, transtornos globais do desenvolvimento e altas habilidades, na educação técnica ou tecnológica em centros de pesquisa de excelência no Brasil e no exterior. O IFP configurou-se como uma medida de ação afirmativa temporária, desenvolvida fora do âmbito do poder do Estado.

Esse programa apresentava muitas especificidades e esteve em vigência no país por um período relativamente longo. Ainda de acordo com a autora Araújo (2015), entre 2002 e 2010, a Fundação Ford, contando com parceiros, dentre eles a Fundação Carlos Chagas, realizou processos seletivos que tinham como objetivo a concessão de bolsas de estudos em cursos de pós-graduação stricto sensu (mestrado e doutorado) para estudantes brasileiros. Para a candidatura eram exigidas algumas condições bem específicas, como o fato de o candidato atender a, no mínimo, um dos critérios estabelecidos: ter nascido nas regiões Norte, Nordeste ou Centro-oeste; identificar-se como negro/a ou indígena; provir de famílias que tiveram poucas oportunidades econômicas ou educacionais e apresentar potencial de liderança e reconhecimento social em seu meio de inserção, pois o IFP apostava que "líderes provenientes de segmentos sociais discriminados seriam mais propensos a abraçar causas e implantar ações visando à diminuição de desigualdades e injustiças sociais" (ROSEMBERG; ANDRADE, 2008, p. 194).

Os programas de pós-graduação, por meio de agências de fomento como a CAPES, fundações próprias ou externas, sempre concenderam bolsas para estudantes aprovados em seus processos seletivos, geralmente baseando-se na ordem de classificaçao dos candidatos. Para a autora Araújo (2015, p. 38), a principal diferença entre a proposição de financiamento do IFP e dos demais programas reside na especificidade da exigência para a candidatura, ou seja, a singularidade dos sujeitos. "São sujeitos que necessariamente pertencem a uma das categorias que o IFP chama de sub-representadas na pós-graduação brasileira, porém possuem forte potencial acadêmico".

Para garantir que fossem eleitos bolsistas que atendessem aos critérios exigidos, o processo seletivo era sempre realizado em três etapas, por diferentes equipes que buscavam alcançar dois objetivos, distintos e complementares, para o Programa: o da ação afirmativa e o do mérito acadêmico. Inicialmente, realizava-se uma avaliação formal, em que o candidato deveria apresentar a sua candidatura de acordo com os critérios do edital de seleção. Embora destinado a categorias com especificidades próprias, a dimensão do mérito não foi relegada. O que torna singular a proposta do IFP é a forma como esse conceito é compreendido. Embora exista a consideração do mérito acadêmico, é importante ressaltar a maneira como esse conceito foi compreendido desde o início do programa. Para os organizadores e consultores, mérito sempre foi compreendido como uma construção social e historicamente localizada, ou seja, o mérito não nasce com os sujeitos e só pode ser atingido por todos à medida que há equidade.

Com base nessas proposições entende-se que o percurso até a pós-graduação não é construído da mesma forma por sujeitos oriundos de grupos étnicos/raciais ou pertencentes a classes sociais distintas. Aquilo que as universidades costumam denominar como mérito, trata-se de um arcabouço de disposições ou condições 
favoráveis que foram constituídas, ativadas e reativadas ao longo das trajetórias escolares e de vida, a partir das múltiplas instâncias em que os sujeitos estiveram (ou ainda estão) inseridos. Considerando a perspectiva do mérito acadêmico, cada candidato encaminhava ao programa um conjunto de documentos que comprovavam as informações prestadas e as possíveis condições de se obter êxito na realização de programas de pós-graduação. A partir da apresentação da candidatura, avaliava-se o pertencimento aos grupos elegíveis e, posteriormente, as condições de mérito acadêmico.

A seleção acontecendo em dois momentos garantia que houvesse justiça aos grupos dentro das categorias de sub-representação e aos sujeitos, individualmente. Conforme a autora Araújo (2015, p. 39), "graças à metodologia adotada, a primeira análise permitia identificar os candidatos que teriam menor chance de concluir o ensino superior e chegar à pós-graduação, e na fase subsequente, dentro do grupo selecionavam-se os indivíduos que apresentavam melhor potencial acadêmico".

Ressalta-se que a importância do IFP foi muito grande, pois além de ter sido uma das primeiras medidas de ação afirmativa na pós-graduação brasileira, tratou-se de um programa que foi muito além da concessão de bolsas ou de cotas para ingresso. Dentre os destaques do programa, além das próprias especificidades do processo de seleção dos candidatos, deve-se considerar a sua importância para a permanência e o sucesso dos bolsistas selecionados. O bolsista era acompanhado de perto durante todo o percurso no programa, do ingresso até a defesa. A primeira fase de acompanhamento foi denominada de "pré-acadêmica" e garantia aos sujeitos a oportunidade de se preparar para os processos seletivos dos Programas de Mestrado e Doutorado no Brasil e no exterior.

A fase pré-acadêmica constituiu-se como um momento de grande importância para os bolsistas, pois representou um fortalecimento acadêmico dos bolsistas em que eles e elas puderam ser acompanhados por um tutor (profissionais de destaque e renome dentro das áreas contempladas pela Fundação Ford), além de fazerem cursos de línguas estrangeiras, adquirirem livros e materiais necessários para a seleção e receberem recursos que Ihes possibilitavam inscrever-se em até quatro processos seletivos bem avaliados pela CAPES. Rosemberg (2013), ao apresentar relatório final do programa, afirma que a participação nessa etapa foi fundamental para que $92,5 \%$ dos bolsistas fossem aprovados em programas avaliados com pelo menos nota 4 pela CAPES.

Ao ingressar no programa, os bolsistas, denominados "bolsistas eleitos", eram recepcionados em Brasília ou São Paulo pela equipe da Fundação Carlos Chagas. Em uma reunião, que durava de dois a três dias, tomavam conhecimento do que seria o programa, dos direitos e deveres, e ainda da fase de orientação e preparação para o ingresso na pós-graduação. Durante essa reunião, cada bolsista tinha a oportunidade de se encontrar com um professor orientador, com quem poderia discutir seu pré-projeto e as possibilidades de orientação pré-acadêmica e de candidatura à pós-graduação, além de orientações sobre os programas mais indicados no Brasil e no exterior. Terminada essa reunião, iniciava-se a fase pré-acadêmica ou Treinamento Pré-acadêmico (TPA), propriamente dita. Ainda que nem todos os bolsistas, por razões variadas, tenham participado dessa fase, ela foi muito importante, pois "sem dúvida nenhuma, o TPA foi uma atividade indispensável para que bolsistas concorressem, com bom ou razoável 
preparo, a vagas no acirrado processo seletivo da pós-graduação brasileira" (ROSEMBERG, 2013, p. 47).

É importante destacar que, destarte a importância da fase pré-acadêmica, o acompanhamento dos bolsistas não se encerrava após o ingresso em algum programa de pós-graduação, permanecia até o momento da defesa. "Essa fase buscava garantir que o objetivo do IFP fosse alcançado, ou seja, que todos os bolsistas pudessem se beneficiar das mesmas oportunidades e que lideranças com forte compromisso social adquirissem uma formação acadêmica de qualidade." (ARAÚJO, 2015, p. 40).

\section{AS TRAJETÓRIAS INVESTIGADAS}

As discussões e reflexões trazidas neste texto são oriundas de entrevistas narrativas episódicas (FLICK, 2002, 2009) realizadas com cinco sujeitos, mestres, formados em programas de pós-graduação em instituições localizadas na região sudeste. Para se chegar a esses sujeitos foi realizada uma busca na página eletrônica da Fundação Carlos Chagas, na qual estão hospedados os perfis de todos os ex-bolsistas do Programa Internacional de Bolsas. Em um segundo momento foram enviadas fichas de identificação eletrônica com a solicitação de informações preliminares e a verificação do interesse em participar de entrevistas sobre a trajetória escolar. Das 58 fichas enviadas, 9 retornaram. Dos nove respondentes, oito se dispuseram a continuar participando da pesquisa, porém por desencontros de agenda e cancelamento do interesse, nem todos os respondentes foram entrevistados.

O grupo final foi constituído por 3 mulheres e 2 homens, autodeclarados negros, com idade entre 40 e 45 anos, moradores de três estados da região Sudeste e um estado da região Centro-oeste. Dos 5, apenas uma bolsista realizou o mestrado em uma instituição particular. Quanto às áreas de formação, foram Educação (3), Direito (1) e Arqueologia (1).

Augusta é advogada e mestra em Direito. Dentre os nove irmãos, foi a única que conseguiu alcançar uma trajetória de longevidade escolar. Conheceu o Programa Internacional de Bolsas por meio do movimento negro e com a bolsa cursou o mestrado em Direito. Atualmente, ela atua como docente em uma universidade estadual em Minas Gerais.

Ana é formada em Pedagogia, nascida no estado de São Paulo, mas vive desde o início da adolescência em Campo Grande, no Mato Grosso do Sul. Filha de uma família numerosa, foi a primeira a chegar ao ensino superior. Com a Bolsa Ford cursou o mestrado em Educação na Universidade de São Paulo, tendo a oportunidade de fazer um intercâmbio no exterior.

Dimir é licenciado em Artes e cursou o mestrado em Educação em uma grande universidade pública federal em Minas Gerais. Teve uma infância difícil, pois nasceu de um relacionamento entre a sua mãe, empregada doméstica, e o filho do patrão. Por intermédio de um amigo que atuava na Pastoral de Rua da Igreja Católica de Belo Horizonte, teve acesso às informações sobre o Programa Internacional de Bolsas da Fundação Ford. 
Marcelo nasceu e sempre viveu no Complexo da Maré, na cidade do Rio de Janeiro. Formado em Geografia, cursou o mestrado com o auxílio da Bolsa Ford na Universidade Federal Fluminense e, no momento da entrevista, em 2015, cursava o doutorado na mesma instituição. Foi estudante de uma das primeiras edições de um cursinho pré-vestibular para jovens negros e carentes, e a partir dessa inserção acessou a universidade e posteriormente o Programa de Bolsas.

Paty nasceu em São Paulo e teve uma infância bem difícil. Paty foi mãe muito jovem e encontrou nos desafios da maternidade forças para construir a sua trajetória de longevidade escolar. O caminho entre o ensino médio e a universidade foi marcado por interrupções. Concluiu o ensino médio por intermédio de um programa de estudos supletivos, ingressou na USP onde cursou Arqueologia e realizou o mestrado na mesma área com o auxílio da Bolsa Ford.

\title{
DISPOSIÇÕES E SUPORTES: ELEMENTOS PARA A COMPREENSÃO DAS TRAJETÓRIAS ESTUDADAS
}

A análise dos cinco perfis de configurações aponta aspectos muito importantes sobre a trajetória de estudantes negros e negras oriundos de meios populares, marcada pelas desvantagens econômicas, bem como a importância da adoção de medidas de ações afirmativas tanto no ensino superior quanto na pós-graduação brasileira. A partir dessa trajetória, buscamos encontrar as disposições e os suportes mobilizados por esses sujeitos para alcançarem a longevidade escolar.

Para Araujo (2015, p. 43), o conceito de disposições pode ser compreendido a partir das elaborações de Lahire $(2002,2004,2005)$

\begin{abstract}
como os hábitos, costumes, tendências ou persistentes maneiras de ser que podem se manifestar ou não ao longo da vida dos indivíduos, de acordo com as múltiplas instâncias de socialização em que estão inseridos. Essas disposições são incorporadas pelos indivíduos e podem ser longas ou breves, dependendo do momento e do contexto em que se manifestam. É importante ressaltar que não se pode falar em disposição a partir de uma única ocorrência, da observação de um acontecimento ou comportamento isolado. A noção de disposição contém a ideia de recorrência, de repetição relativa, e supõe a observação de situações coerentes.
\end{abstract}

As disposições são produtos de práticas socializadoras incorporadas. Portanto, não se constituem em episódios isolados, mas a partir de experiências relativamente semelhantes que se repetem. Uma disposição não pode ser considerada como uma resposta mecânica a determinados estímulos, mas como maneiras de ver, sentir e agir que podem se ajustar a determinados contextos ou situações encontradas. Porém, a possibilidade de ajuste não é a única; existe o caráter de alternância das disposições: uma disposição pode ser reforçada por solicitação contínua ou desativada e pode ser transformada ou enfraquecida por falta de utilização. Não se incorpora um hábito constante ou durável em poucos instantes, da mesma forma que, por não encontrarem condições para atualização ou permanência, disposições constituídas em determinados momentos de algumas trajetórias podem ser apagadas ou enfraquecidas. Podem, ainda, 
ocorrer na forma de crenças (disposições para crer) e de ações (disposições para agir). Os indivíduos podem incorporar valores e normas (crenças), mas não possuir as condições necessárias para colocá-las em ação, ou seja, concretizá-las. Nesse sentido, não se pode pressupor que uma crença é exatamente uma disposição para agir.

Para Lahire (2002, p. 60), durante a trajetória de vida os indivíduos se inserem em múltiplos e variados contextos de socialização. Assim, estão sujeitos a formas e processos variados de interações. Nesses processos é que as disposições são constituídas e postas à espera. Sua ativação ou reativação vai depender da situação vivenciada, ou seja, das interações entre os atores, do ciclo de vida e das condições específicas de socialização. Um conjunto de disposições construído na infância pode ficar em vigília e só vir a ser reativado na adolescência ou na idade adulta, diante de novos agentes desencadeadores. Essas agentes podem ser novas situações ou condições de vida, como mudanças, associações a grupos, participações em movimentos culturais e casamentos, entre outros.

Ao analisarmos as trajetórias, notamos que para que os sujeitos desenvolvessem disposições para a longevidade escolar puderam contar com muitos suportes ao longo da vida pessoal e acadêmica. Compreendermos suportes, na perspectiva de Martuccelli (2012), como os apoios recebidos para que pudessem estar onde estão hoje. Nenhum indivíduo existe sem suporte, no entanto o que pode ser suporte para uma pessoa nem sempre o será para outra.

[...] em muchos casos los soportes pueden ser una actividad laboral, para otros, pueden constituir-los ciertos vínculos sociales privilegiados (lapareja, una persona referente, amigos), em otros puede tratar-se de una acción de consumo cultural -pienso em la lectura pero también, por supuesto em la televisión- y sería fácil alargar la lista. ¿ Qué tienen em común todos estos factores? Que en todos los casos, para poder "soportar" la existencia, su "peso", los indivíduos tienen que encontrar, dar-se, soportes em el mundo social. (MARTUCCELLI, 2102, p. 36).

Dessa maneira, para alguns os suportes foram encontrados dentro da própria família. Para outros, vieram de pessoas de fora do seu núcleo familiar, amigos e conhecidos. Alguns encontraram suporte na própria escola. Existiram os suportes materiais, como recursos financeiros para custear determinados cursos, e imateriais, como o incentivo e a orientação em certas ocasiões. Ouvindo os depoentes fica evidente que nem todos os atores sociais vão poder dispor dos mesmos suportes e que os suportes têm efeitos diferentes para cada um, em consonância com o que já afirmou Martuccelli (2012).

Assim como nem todos os indivíduos se beneficiam dos mesmos suportes, existem suportes mais legítimos socialmente e outros menos. A leitura pode ser considerada como um suporte mais legítimo que a televisão. Mas mesmo esses dois suportes atuam de maneira diferente para cada ator social, pois um objeto ou ação para serem considerados suportes dependerão das condições individuais de existência. Existem suportes tão legítimos que se tornam "socialmente invisíveis", transmitindo a 
ARAÚJO, M. B. DE.; SILVA, S. A. DA.

noção de que alguns indivíduos que usufruem de certos privilégios sociais, culturais e econômicos existem e se constituem sem suportes. São esses indivíduos que parecem existir por si mesmos e que são considerados como "grandes homens", os que têm atrás de si um grande conjunto de suportes. Por serem esses suportes tão legítimos, tornamse invisíveis. Ao contrário, aqueles que dependem de suportes considerados ilegítimos, como os benefícios sociais, são considerados frágeis e incapazes de sobreviver por si mesmos. Paradoxalmente, são esses os que, para a sociologia dos suportes, possuem maior capacidade de existirem por si mesmos e suportarem a si próprios (MARTUCCELLI, 2012).

\section{DISPOSIÇÕES DESENVOLVIDAS E SUPORTES RECEBIDOS}

Para cada sujeito entrevistado, as disposições para a longevidade escolar foram construídas em tempos e espaços diversos, variando de acordo com os suportes que cada um recebia. Embora a pesquisa tenha trabalhado com trajetórias individuais, foi possível perceber que algumas instituições sociais, por meio de seus agentes, atuaram como suporte em mais de uma trajetória.

A escola básica (ensino fundamental e médio) esteve presente como relevante em todas as trajetórias, com exceção do caso de Ana. Em algumas, desde os anos iniciais, e em outras, a partir do ensino médio. Augusta, que nasceu em uma cidade do interior de Minas e se tornou mestre em Direito, recorda com carinho do momento da formatura da quarta série, que era realizada em uma cidade próxima a sua com toda pompa e circunstância. E foi ali, na educação básica, que ela começou a desenvolver as suas disposições para a longevidade escolar, a partir do gosto pelo estudo, do capricho com os cadernos e do prazer em estar na escola. Ainda que tivesse passado por momentos ruins nessa fase da sua trajetória escolar, foi nesse espaço que ela conheceu uma professora que lhe incentivou a estudar, a prosseguir e, também, contribuiu para que ela conseguisse perceber que a história do povo negro foi de sofrimento, mas, sobretudo, de resistência.

Para Dimir, que cresceu sozinho em uma região de grande vulnerabilidade, a escola básica era o espaço da alegria. E foi também na escola que ele começou a desenvolver suas disposições para a construção de uma trajetória longa e de sucesso escolar. Algumas experiências contribuíram de modo especial para essas disposições: uma visita ao museu no ensino fundamental e o protagonismo em uma peça de teatro no ensino médio.

Paty, mestre em arqueologia, também encontrou na escola suportes para desenvolver as disposições iniciais para a longevidade por meio de uma professora, que em um momento delicado da vida da entrevistada, teve a sensibilidade de perceber a fragilidade e ao mesmo tempo o potencial acadêmico da aluna e a incentivou a prosseguir nos estudos.

Marcelo, mestre em educação, cresceu em um morro no Rio de Janeiro e só começou a se interessar pela escola e desenvolver realmente as disposições para a longevidade no ensino médio. Nesse caso, ele teve um suporte muito importante, um professor que levou sua turma para uma visita técnica a uma universidade. Essa experiência mudou a sua forma de olhar para a educação e para a escola. 
Para Ana, mestre em educação, o trabalho foi um grande mobilizador, pois assim que recebeu o título de professora dos anos iniciais, ainda no ensino médio, começou a trabalhar e se inseriu em uma escola que incentivava os professores a estudar e progredir na carreira. Essa escola atuou com um importante suporte em sua trajetória. É importante ressaltar que o efeito do trabalho com mobilizador para a construção de suas disposições ascéticas pelo estudo esteve presente desde antes da conclusão do ensino médio. Ainda no ensino fundamental, ela teve uma experiência negativa com o trabalho, pois trabalhando como doméstica viu muitas pessoas serem humilhadas pelos patrões. A partir dessa experiência decidiu que iria estudar, pois queria ter uma profissão mais valorizada socialmente.

Dimir também encontrou no trabalho muitos suportes necessários para a constituição da sua longevidade escolar. Foi no trabalho que ele encontrou um senhor que o apresentou para um vereador que, por sua vez, Ihe concedeu uma bolsa de estudos para cursar o ensino médio, em uma época em que as escolas públicas que ofertavam esse nível de ensino eram pouquíssimas e as particulares praticamente inacessíveis.

Em algumas trajetórias os professores se constituíram como importantes suportes, como na trajetória de Paty, que teve uma professora que a acolheu. Para Marcelo, o professor que o levou para conhecer a universidade e promovia debates na escola, por meio dos quais ele pôde se conscientizar da realidade social na qual estava inserido e despertar o desejo de agir sobre ela, tendo a educação como projeto, foi um importante suporte. Augusta encontrou na escola uma professora de história que a fez desejar prosseguir nos estudos.

Destacamos também a importância do suporte do movimento negro nas trajetórias de Augusta, Ana e Marcelo. Durante a graduação, Augusta e Ana tiveram uma formação paralela, pois os encontros organizados por esse movimento proporcionavam leituras e reflexões que contribuíam para seu desempenho acadêmico. Para Marcelo, a participação em um cursinho preparatório para estudantes negros e carentes ${ }^{3}$ foi um suporte importante para que ele fosse aprovado no vestibular e conseguisse se inserir na universidade de forma menos traumática.

Em todas as trajetórias as famílias também estiveram presentes, porém de maneiras diferentes. No caso de Paty, que ora vivia com a mãe ora com o pai, viver em um lar (a casa paterna) onde eram desenvolvidas disposições favoráveis à escolarização e a práticas de leitura foi importante para o seu percurso de longevidade escolar, como ela mesma atesta.

\footnotetext{
Eu fui alfabetizada antes de entrar na escola. Eu tenho uma tia que era formada em Letras então ela me alfabetizou, sei lá, um ano antes de entrar para escola primária. Eu sempre tive acesso a livros. Eu sempre gostei de estudar. Sempre gostei de ler. Acho que isso aí foi um ponto positivo para eu estar hoje fazendo o doutorado. Minha tia também lia muito. Esse estímulo que eu tive logo na infância. Eu tive acesso a esses livros disponíveis. (ENTREVISTA concedida em 2015).
} 
Para Paty, a presença significativa da tia contribuiu para despertar na sobrinha o gosto pelo estudo. As práticas de leitura realizadas em casa são suportes mobilizados pelas famílias, especialmente das classes médias, que contribuem positivamente para o sucesso escolar de seus filhos. Quanto aos demais bolsistas, a participação da família na vida escolar foi aquém do esperado pela escola, pois os responsáveis não frequentavam as reuniões, não olhavam os boletins e, menos ainda, ajudavam os filhos nas atividades que eram levadas para casa, até porque lhes faltavam competências para isso, por não terem conhecimento escolar. No entanto, havia uma cobrança, "através da cinta", de que os filhos apresentassem bons resultados, como no caso de Marcelo. A postura de cobrar de forma dura e incisiva o bom desempenho dos filhos, expresso por meio das notas no boletim, contraria o "mito da omissão parental" (LAHIRE, 2004) produzido por professores, que a partir do comportamento de estudantes diante do conhecimento escolar acreditam que as famílias não se preocupam com os filhos, deixando-os à própria sorte, fazendo o que bem entendem. "[...] para bater nos filhos, é também necessário julgar que isso vale à pena e conferir à escola um mínimo de importância e valor" (LAHIRE, 2004, p. 335). Assim, embora pela narrativa de Marcelo a escola dos anos iniciais pareça não ser muito representativa para ele, a fim de corresponder às expectativas da mãe ele foi desenvolvendo algumas estratégias que podem ter contribuído para a sua escolarização prolongada, como o fato de prestar atenção às aulas e realizar as tarefas propostas dentro da escola para não precisar estudar em casa.

E, finalmente, dentre todos os suportes, o Programa Internacional de Bolsas se destaca porque esteve presente em todas as trajetórias, e porque, para alguns, chegou em um momento em que, sem esse suporte, seria muito mais difícil o ingresso e a permanência na pós-graduação. A pós-graduação representou uma nova experiência de escolarização na vida de cada um dos bolsistas entrevistados, pois foi nesse momento, por meio de um programa de ação afirmativa, que tiveram a oportunidade de viver integralmente o papel de estudante. Romanelli (2000) apresenta três tipos de estudantes, aquele que pode se dedicar totalmente aos estudos; o estudante trabalhador, que trabalha, mas ainda depende financeiramente de seus familiares, e o trabalhador-estudante, aquele que, além de não depender financeiramente da família, muitas vezes, precisa contribuir para o orçamento doméstico.

\section{CONSIDERAÇÕES FINAIS}

Na perspectiva de apresentar algumas reflexões que possibilitem o fechamento de algumas discussões realizadas ao longo do texto, retomaremos alguns pontos apresentados. O conhecimento e a análise dos percursos escolares e das trajetórias de vida dos cinco sujeitos apresentados nos possibilitou reafirmar uma constatação já apresentada por Souza (2009), que longos e exitosos percursos escolares não se constroem em espaços únicos e nem sob uma única influência. Assim, nas análises de trajetórias é sempre necessário considerar-se a individualidade, mas também a teia de relações sociais nas quais o sujeito está inserido.

Embora algumas disposições para a longevidade escolar possam até ser constituídas na infância, o indivíduo só conseguirá traçar um longo percurso acadêmico 
se encontrar condições e suportes favoráveis (ARAÚJO, 2015). Nas trajetórias estudadas, quatro instituições se destacaram: a escola (e seus professores), a família, o movimento negro e o Programa Internacional de Bolsas da Fundação Ford. Os suportes encontrados nessas instituições tiveram pesos diferenciados em cada trajetória, com exceção do Programa Internacional de Bolsas. Augusta, Ana e Marcelo encontraram no movimento negro apoio para ingressar, permanecer ou concluir o ensino superior. Paty teve um apoio maior da família. Para Dimir, a escola e o trabalho foram os suportes mais significativos em alguns momentos. Cabe ressaltar a importância do IFP para a formação acadêmica e a conclusão dos estudos de pós-graduação.

Em todos os casos analisados, os indivíduos já possuíam um potencial, mas para permanecer e concluir com êxito programas de pós-graduação, em um sistema considerado de excelência como a pós-graduação no Brasil, o apoio desse programa nas diversas fases foi fundamental. Como afirmou Augusta, realizar o mestrado não resolveu todos os seus problemas, mas lhe possibilitou refletir sobre a educação e a necessidade de se investir cada vez mais nessa área. Poder se dedicar aos estudos sem se preocupar em ter que trabalhar para se manter a fez pensar nas condições da educação no País e na importância e necessidade das ações afirmativas para a graduação e pós-graduação.

Artigo recebido em: 10/07/2020

Aprovado para publicação em: 13/10/2020

ACCESS TO POSTGRADUATE: SOME TRAJECTORIES AND EXPERIENCES OF ACCESS BY AFFIRMATIVE ACTIONS

ABSTRACT: These are discussions about the trajectories of black subjects who have accessed and concluded Stricto Sensu Postgraduate (master's level) with the help of an affirmative action program at the postgraduate level, the Ford Foundation International Fellowships Program. It was possible to know and analyze the school and life paths of five subjects by using the qualitative research resources, such as the narrative episodic interview and the construction of sociological portraits. For the construction of trajectories as long as unlikely, the investigated subjects were developing and reactivating their dispositions in several spaces and moments, counting, besides their own desire, with the participation of the school, families and organized social movements, with emphasis on the Black Movement.

KEYWORDS: Affirmative Actions. Postgraduate. School trajectories. Social movements.

ACCESO A LA POST-GRADUACIÓN: ALGUNAS TRAJETORIAS Y EXPERIENCIAS DE ACCESO POR MEDIO DE ACCIONES AFIRMATIVAS

RESUMEN: Se trata de discusiones acerca de las trayectorias de sujetos negros y de medios populares que accedieron y concluyeron Programas de Postgrado Stricto sensu (nivel de maestría) con el auxilio de un programa de acciones afirmativas en el postgrado, el Programa Internacional 
ARAÚJO, M. B. DE.; SILVA, S. A. DA

de Becas de la Fundación Ford. Basándose en los recursos de la investigación cualitativa, por medio de la entrevista narrativa episódica y la construcción de retratos sociológicos fue posible conocer y analisar las trayectorias de cinco sujetos (as). Para la construcción de trayectorias tan largas cuanto improbables, los sujetos investigados fueron desarrollando y reactivando sus disposiciones en varios espacios y momentos, contando, además del propio deseo, con la participación de la escuela, de las familias y de los movimientos sociales organizados, con destaque para el Movimiento negro.

PALABRAS-CLAVE: Acciones afirmativas. Posgraduación. Trayectorias escolares. Movimientos sociales.

\section{NOTAS}

1) Título da dissertação: Longevidade escolar nos meios populares: disposições e estratégias dos bolsistas de Pós-graduação do Programa Internacional de Bolsas de Pós-Graduação da Fundação Ford (International Fellowships Programa)

2) Para Domingues (2007), movimento negro pode ser compreendido como a luta organizada dos negros na perspectiva da busca pela resolução de problemas e conflitos sociais, em particular aqueles oriundos dos preconceitos e das discriminações raciais, que os discriminam e os colocam à margem no mercado de trabalho, no sistema educacional, político, social e cultural.

3) Esses cursinhos foram muito importantes para o acesso ao ensino superior, pois além das especificidades da preparação para a realização dos exames vestibulares, incluía nos currículos uma disciplina chamada "Cultura e Cidadania". Para Santos (2007), essa disciplina que objetiva a realização de um trabalho de politização com base em conteúdos e disciplinas que não são trabalhados em cursos pré-vestibulares tradicionais, se tornou uma prática cristalizada e repetida, pelo menos em tese, em todos os núcleos do PVNC. É importante ressaltar que esses cursinhos nascem como estratégias para a elevação da escolarização das bases sociais do movimento negro, a partir de discussões realizadas nos anos de 1980, sobretudo nos espaços da Pastoral do Negro.

\section{REFERÊNCIAS}

ARAÚJO, Márcia Basília de. Longevidade escolar nos meios populares: disposições e estratégias dos bolsistas de Pós-graduação do Programa Internacional de Bolsas de Pósgraduação da Fundação Ford (International Fellowships Programa) . 2015. $127 \mathrm{f}$. Dissertação (Mestrado em Educação) - Faculdade de Educação, Universidade do Estado de Minas Gerais, Local, Belo Horizonte, 2015.

COORDENAÇÃO DE APERFEIÇOAMENTO DE PESSOAL DO ENSINO SUPERIOR. Plano nacional da pós-graduação (PNPG) 2011-2020: documentos setoriais, v. 2. Brasília, 2010.

em: https://www.capes.gov.br/images/stories/download/PNPG_Miolo_V2.pdf. Acesso em: 17 jul. 2104. 
COORDENAÇÃO DE APERFEIÇOAMENTO DE PESSOAL DE NÍVEL SUPERIOR. GEOCAPESSistema de Informações Referenciadas Georreferenciadas: [indicadores]. Brasília, 2018. Disponível em: https://geocapes.capes.gov.br/geocapes/. Acesso em: 2 jan. 2019.

DOMINGUES, P. Movimento negro brasileiro: alguns apontamentos históricos. Tempo, $\mathrm{n}$. 23, p. 100-122, 2007. Disponível em: https://www.scielo.br/pdf/tem/v12n23/v12n23a07.pdf . Acesso em: 19 out. 2020.

FLICK, U. Introdução à pesquisa qualitativa. 3. ed. Porto Alegre: Bookman, 2009.

FLICK, U. Entrevista episódica. In: BAUER, M. W; GASKELL, G. Pesquisa qualitativa com texto: imagem e som: um manual prático I. Petrópolis: Vozes, 2002. p. 114-137.

INSTITUTO BRASILEIRO DE GEOGRAFIA E ESTATÍSTICA. Síntese dos indicadores sociais: uma análise das condições de vida da população brasileira 2017. Rio de Janeiro, 2018. Disponível em: https://biblioteca.ibge.gov.br/visualizacao/livros/liv62715.pdf. Acesso em: 15 dez. 2018.

LAHIRE, B. O homem plural: os determinantes da ação. Petrópolis: Vozes, 2002.

LAHIRE, Bernard. Patrimónios individuais de disposições: para uma sociologia à escala individual. Sociologia, n. 49, p. 11-42, set. 2005 . Disponível em: http://www.scielo.mec.pt/pdf/spp/n49/n49a02.pdf . Acesso em: 17 dez. 2018.

LAHIRE, Bernard. Retratos sociológicos: disposições e variações. [S.I.]: Artmed, 2004.

LAHIRE, Bernard. Sucesso escolar nos meios populares: as razões do improvável. São Paulo: Ática, 2004a.

MARTUCCELLI, D. Lecciones de sociología del indivíduo. 2. ed. Lima (Peru): PUCP. Departamento de Ciencias Sociales, 2007. Disponível em: http://departamento.pucp.edu.pe/ciencias-sociales/files/2012/06/MartuccelliLecciones_de_sociologia_del_individuo2.pdf. Acesso em: 19 ago. 2018.

MEC. Ministério da Educação. Conselho Nacional de Educação. Portaria $\mathrm{CNE} / \mathrm{CP} \mathrm{n}^{\circ} 4$, de 31 de maio de 2011. DOU, Brasília, Seção 1, p. 8, 2011. Disponível em: http://portal.mec.gov.br/index.php?option=com_docman\&view=download\&alias=8140 -port004-11\&ltemid=30192. Acesso em: 16 out. 2012.

ROMANELLI, G. Famílias de camadas médias e escolarização superior dos filhos: o estudante trabalhador. In: NOGUEIRA, M. A.; ROMANELLI, G.; ZAGO, N. (Org.). Família e escola: trajetórias de escolarização em camadas médias e populares. Petrópolis: Vozes, 2000. p. 99-123. 
ARAÚJO, M. B. DE.; SILVA, S. A. DA

ROSEMBERG, F. Ação afirmativa na pós-graduação: o Programa Internacional de Bolsas da Fundação Ford na Fundação Carlos Chagas. São Paulo: FCC/SEP, 2013.

ROSEMBERG, F.; ANDRADE, L. F. Ação afirmativa no ensino superior brasileiro: a tensão entre raça/etnia e gênero. Cadernos Pagu, Campinas, n. 31, p. 419-437, 2008. Disponível em: $\quad$ https://www.scielo.br/scielo.php?pid=S0104$83332008000200018 \&$ script=sci_abstract\&tlng=pt. Acesso em: 17 dez. 2018.

SANTOS, S. A. (Org.). Ações afirmativas e combate ao racismo nas Américas. Brasília: UNESCO/MEC, 2007. (Coleção Educação para todos).

SILVÉRIO, V. R. O IFP e a ação afirmativa na pós-graduação brasileira. In: ZONISSEIN, J.; FERES JÚNIOR, J. (Org.). Ação afirmativa no ensino superior brasileiro. Belo Horizonte: UFMG, 2008. p. 215-241.

SOUZA, M. S. N. M. Do seringal à universidade: o acesso das camadas populares ao ensino superior público no Acre. 2009. 209 f. Tese (Doutorado em Educação) - Faculdade de Educação, Universidade Federal de Minas Gerais, Local, Belo Horizonte, 2009. Disponível em: https://repositorio.ufmg.br/handle/1843/FAEC-83WR2W. Acesso em: 17 dez. 2018.

Márcia Basília de Araújo: Possui graduação em Pedagogia pela Universidade do Estado de Minas Gerais (1996), mestrado em Educação pela Universidade do Estado de Minas Gerais (2015) e doutorado em Educação pela Universidade Federal de Minas Gerais. Atualmente é pedagoga do Instituto Federal de Minas Gerais.

Orcid: https://orcid.org/0000-0002-4109-4934

E-mail: marciabasiliaaraujo@gmail.com

SantuZa AmOrIM dA SILVA: Graduou-se em Biblioteconomia pela Universidade Federal de Minas Gerais (1993) e Licenciatura em História (PUC/MG). Possui mestrado em Educação (1997), doutorado em Educação (2007) pela Universidade Federal de Minas Gerais, doutorado sanduíche pelo INRP (Institut Nacional de Recherche Pédagogigue). Realizou estágio de pós-doutorado na Université Paris 8 (2011/12). Atua como professora no Curso de Pedagogia e no Mestrado em Educação da Universidade do Estado de Minas Gerais.

Orcid: https://orcid.org/0000-0001-8711-5377

E-mail:santuza@hotmail.com

Este periódico utiliza a licença Creative Commons Attribution 3.0, para periódicos de acesso aberto (Open Archives Iniciative - OAI).

Inter-Ação, Goiânia, v.45, n.3, p. 954-968, set./dez. 2020. Disponível em:<http://dx.doi.org/10.5216/ia.v45i3.64404>. 